\title{
Assessing perceptions of COVID-19 self-protective measures: a structural equation modeling (SEM) approach
}

\author{
Sangeeta Mehrolia, Subburaj Alagarsamy and Jeevananda S. \\ School of Business and Management, Christ University, Bangalore, India
}

\begin{abstract}
Purpose - This study aimed to develop scales to assess perceptions of coronavirus disease 2019 (COVID-19) self-protective measures (SPMs) and examine the psychometric properties based on the theory of planned behavior (TPB).

Design/methodology/approach - A total of 412 participants from Bangalore, India, randomly volunteered to participate in this research. The questionnaire consisted of items related to the TPB scales and demographic details.

Findings - A structural equation model showed a reasonable model fit. In total, $70 \%$ of the individuals' behavioral intentions of following COVID-19SPMs were predicted by perceived benefits, barriers, social norms and social influence. Participants' age impacted on perceived benefits and perceived social influence and individuals' behavioral intentions of following COVID-19 SPMs, with a 13.6\% difference in model prediction. Originality/value - The TPB can be used as a strong psychometric property to assess behavioral determinants of COVID-19 SPMs.
\end{abstract}

Keywords COVID-19, Self-protective measures, Theory of planned behavior, Perceived social norms,

Social influence

Paper type Research paper

\section{Introduction}

The world is currently facing a global health crisis - one that has caused suffering and has upended the lives of the people. However, this is far more than just a health issue. It is a problem that impacts on the international economy and society. The World Health Organization (WHO) has described the coronavirus disease (coronavirus disease 2019 [COVID-19]) as a pandemic attacking countries at its core. If the social crisis created by the COVID-19 pandemic is not appropriately addressed, inequality, exclusion, discrimination and medium- and long-term global unemployment may also increase. Older people, particularly those with chronic health conditions, are especially vulnerable to the risk of contracting the COVID-19 infection [1].

To date, there is no cure for COVID-19. Many Countries have instituted various degrees of lockdowns to prevent the further spread of COVID-19. Some include total control of movement, while others have enforced time-based restrictions. In India, the nationwide lockdown was enforced on March 24, 2020, and this was further extended until May 31, 2020. Due to the lockdown, the growing rate of COVID-19 cases and deaths has also fallen dramatically. However, now that the lockdown has been lifted, COVID-19 cases are on the

(c) Sangeeta Mehrolia, Subburaj Alagarsamy and Jeevananda S. Published in Journal of Health Research. Published by Emerald Publishing Limited. This article is published under the Creative Commons Attribution (CCBY 4.0) licence. Anyone may reproduce, distribute, translate and create derivative works of this article (for both commercial and non-commercial purposes), subject to full attribution to the original publication and authors. The full terms of this licence may be seen at http://creativecommons. org/licences/by/4.0/legalcode 
JHR 35,4

\section{8}

increase in India [2]. There is a risk that infection rates will increase again faster than the first wave.

India is currently facing a threefold burden of diseases - infectious diseases, the threat of noncommunicable diseases and the rise of COVID-19. India's current health system continues to be overstretched and needs to be reinforced to address these challenges. India does not have the necessary infrastructure or financial resources to cope with a significant public health crisis according to global health experts. Extreme shortages of medical personnel and supplies are also present in India. Health-care spending in India needs to be increased to at least the global level, which should concentrate on both preventive and curative treatment. In the current situation, there is an immediate need to make a significant contribution to the annual funding of health care in India. Priority should be given to building more laboratories and clinics, storing test kits and developing indigenous vaccines. In addition, spending on research and raising awareness of public health disasters is another field that requires attention. In fixing the gap in medical developments and research to provide better treatment at all levels, the government faces problems. There is a need to scale-up public health facilities, the number of beds and doctors, medical supplies, medication and treatment packages for public health emergencies when looking at the severity of COVID-19 [2]. As of November 6,2020, the total number of cases was 8,411,724 with total confirmed cases of 125,029 deaths and 7,765,966 recovered in India.

The Indian health ministry stated that "We must learn to live with COVID-19. It is possible that with adherence to social distancing norms, India may never hit the peak." Based on recent government advice, it is clear that individual responsibility toward following selfprotective measures [SPMs] can effectively control the spread of COVID-19 [3].

The WHO has advised everyone to follow SPMs. SPMs include social distancing, washing hands regularly with soap or using $60 \%$ alcohol-based hand sanitizers, throwing used tissues and masks into closed bins, avoiding mass gatherings, using face masks and washing hands before touching the eyes, nose and mouth. Studies indicate that SPMs are effective in reducing the spread of COVID-19. However, the effective use of these SPMs depends on an individual's mindset. Factors including an individual's age, knowledge, risk perception, belief, social and norms influence, perceived benefits and barriers influence the use of SPMs and their engagement in safe behaviors [4]. Identifying the impact of these factors on SPMs will provide better insight into individuals to follow safety behaviors [5]. These factors have seldom been examined in a comprehensive study. Many studies have focused on studying SPMs and the impacts of demographics and governmental regulations on SPMs [6, 7]; however, studies assessing the individuals' intention to use the SPMs related to COVID-19 are limited. Individuals' behavioral intentions are complex, and it is necessary to adopt a dynamic approach in this research. Having a specific theoretical framework could improve our understanding of individuals' behavior within the context of COVID-19. In this study, we used the theory of planned behavior (TPB) to understand factors and paths by which these factors may influence the adoption of the SPMs by individuals.

\section{Theory of planned behavior}

The TPB is the most frequently adopted instrument since its inception that is used to envisage human behavior [8], mainly in the field of public health $[9,10]$. The TPB helps researchers to predict the intentions of the individual to adopt specific behaviors. The intention behind adopting SPMs during pandemic times depends on the perceived benefits of adopting such measures, perceived barriers and perceived social norms and influences [11]. The extent to which an individual quantifies the benefits and barriers decides a change in behavioral intentions. Adoption will be faster if the risk is more and barriers are low. For example, the consumer always intends to buy healthy and safe products if there is a high risk 
of contagious disease [12]. Many studies explain that the intention to change any habit will develop only when the prevailing fear of human life is instilled in the surroundings. In the COVID-19 scenario, this perceived risk in the eyes of friends, family and relatives is high, and this forces people to select healthy and safe options $[13,14]$.

Social norms are perceived as clues that pressurize individuals to adopt or not to adopt certain behaviors. Social norms and social influence in the present context are related to the opinion of important people in our lives $[14,15]$ but also to the social environment [16]. Change in individual behavior is sometimes forceful and perceived as induced from outside rather than internally motivated. An individual as a social animal usually seeks psychological approval from society $[14,17]$. In the current context, change in people's behavior can be related to social norms and social influence. This study aims to develop scales to assess perceptions related to COVID-19 SPMs and examine the psychometric properties based on the TPB and whether these factors are moderated by the age of the participants.

\section{Methods}

The questionnaire consisted of items related to the theory of planned behavior scales (TPBS) and demographic details such as gender, age and residence of the respondent. The original 22 -item TPBS was modified in relation to COVID-19 SPMs and was adopted from a previous study [14].

The modified TPBS contained 19 items and was measured on a Likert scale ranging from 1 to 7 , with $1=$ "Extremely strongly disagree" and 7 = "Extremely strongly agree." To assure their content validity, researchers in the area of behavioral science gave feedback on the scale items. Some items were irrelevant and were consequently removed from the questionnaire.

A cross-sectional design was used, and a well-structured questionnaire was distributed through online forums. The cover letter described the voluntary nature and aim of the study, which was detailed on the first page of the questionnaire. Participants are asked to give their consent after reading the cover letter. The SPMs digital infographics published by the WHO was attached to the online questionnaire. Participants were asked to check the SPMs digital infographics before answering the questionnaire and were requested to answer the questionnaire based on their perception toward following those recommended self-protective precautions.

A total of 412 participants randomly volunteered to participate in this research. The data were collected from Bangalore, India. Bangalore has a population of more than $8 \mathrm{~m}$ and a metropolitan population of around $11 \mathrm{~m}$, making it the third most populous city and fifth most populous urban agglomeration in India.

In India, 79\% of COVID-19 total cases on May 17, 2020, were from only 30 cities but soon started to progress from urban to rural areas in India [18]. Understanding the SPMs usage in Bangalore can be generalized to other metropolitan cities in India. For this reason, Bangalore city was selected as the study area. Demographical data concluded that $49.8 \%$ of the participants were female and $50.2 \%$ of the participants were male. The mean age of participants was 29.76 years, with a standard deviation of 8.44 years. In total, $61.9 \%$ of the participants were from an urban area; $23.1 \%$ of the participants were from semiurban and the remaining $15.0 \%$ participants were from a rural area. Most of the participants $(70.4 \%)$ had a bachelor's degree, $24.0 \%$ of the participants had a master's degree and $5.6 \%$ of the participants had up to schoollevel qualifications. Most participants belonged to the employed category (42.5\%); $22.6 \%$ of the participants were engaged in business, $20.4 \%$ of the participants were students and the remaining $14.6 \%$ of the participants belonged to the unemployed and retired categories.

Univariate statistical analysis and multivariate statistical analysis were used in this study. IBM SPSS 25 and IBM AMOS 25 software packages were used to analyze the data. 
Ethical approval for this study was submitted and approved by the Research Conduct and Ethics Committee (CU: RCEC/19/05/20), Center for Research, CHRIST (Deemed to be University), Bengaluru - 560029, India.

\title{
Results
}

The research instrument adopted for this study was already validated in another context; hence, confirmatory factor analysis was carried out to verify the factor structure of a set of observed variables and the reliability and validity of the constructs by developing a measurement model. A similar approach was followed by many public health domain studies. Convergent validity and discriminant validity were used to explain the construct validity. Cronbach's alpha $[\alpha]$, composite reliability (CR), average variance extracted (AVE) and statistical significance of individual item factor loadings $(\beta)$ were used to assess the convergent validity [19]. Table 1 and Figure 1 show that the item factor loadings $(\beta)$ were higher than 0.5 and significant at the $1 \%$ level $(p<0.01)$, and all the items were retained. Table 2 shows the reliability and validity of the statistics. These measures were above the recommended levels (i.e. $0.7>\alpha ; 0.7>$ CR; $0.5>$ AVE), indicating acceptable levels for the reliability of constructs [19] and support for the convergent validity. Discriminant validity was inferred when measures of each construct converged on their respective true scores,

\begin{tabular}{|c|c|c|c|}
\hline Code & Statement & $\beta$ & $p$-value \\
\hline \multicolumn{4}{|c|}{ Perceived barriers (mean $=4.34 ; S D=1.76)$} \\
\hline BA1 & Following COVID-19 SPMs would take too much time & 0.880 & $0.001 * *$ \\
\hline BA2 & Following COVID-19 SPMs would cost too much & 0.892 & $0.002^{* *}$ \\
\hline BA3 & Following COVID-19 SPMs would be dependent on the location of the program & 0.732 & $0.001^{* *}$ \\
\hline \multicolumn{4}{|c|}{ Perceived benefits (mean $=5.38 ; S D=1.24$ ) } \\
\hline BE1 & Following COVID-19 SPMs would be beneficial & 0.853 & $0.001 * *$ \\
\hline BE2 & Following COVID-19 SPMs would be pleasant & 0.682 & $0.001^{* *}$ \\
\hline BE3 & Following COVID-19 SPMs would decrease my chances of getting COVID-19 & 0.907 & $0.001^{* *}$ \\
\hline BE4 & Following COVID-19 SPMs would improve my health performance & 0.765 & $0.002^{* *}$ \\
\hline BE5 & Following COVID-19 SPMs would improve my knowledge about COVID-19 & 0.730 & $0.001^{* *}$ \\
\hline \multicolumn{4}{|c|}{ Perceived social norms (mean $=5.78 ; S D=1.26$ ) } \\
\hline PSN1 & Most people who are important to me approve of and follow COVID-19 SPMs & 0.891 & $0.001^{* *}$ \\
\hline PSN2 & My family members approve of and follow COVID-19 SPMs & 0.902 & $0.002^{* *}$ \\
\hline PSN3 & My teammates/friends approve of and follow COVID-19 SPMs & 0.905 & $0.001^{* *}$ \\
\hline \multicolumn{4}{|c|}{ Perceived social influence (mean $=5.72 ; S D=1.32$ ) } \\
\hline SI1 & If my society was following COVID-19 SPMs, I would be more likely to participate & 0.834 & $0.001^{* *}$ \\
\hline SI2 & $\begin{array}{l}\text { If there was evidence that COVID-19SPMs reduce the chance of spreading COVID- } \\
19 \text {, I would be more likely to follow }\end{array}$ & 0.768 & $0.002^{* *}$ \\
\hline SI3 & If society was following COVID-19 SPMs, I would follow too & 0.863 & $0.002^{* *}$ \\
\hline \multicolumn{4}{|c|}{ Behavioral intention to follow (mean $=5.86 ; S D=1.11$ ) } \\
\hline INT1 & I am confident that I can follow COVID-19 SPMs & 0.902 & $0.001^{* *}$ \\
\hline INT2 & If I had access to COVID-19 SPMs, I would be more likely to follow & 0.850 & $0.002 * *$ \\
\hline INT3 & I intend to follow COVID-19 SPMs & 0.935 & $0.001 * *$ \\
\hline INT4 & If I was given COVID-19 SPMs to perform at home, I would follow & 0.858 & $0.001^{* *}$ \\
\hline INT5 & If a health-care provider conducted COVID-19SPMs online session, I would attend & 0.599 & $0.001 * *$ \\
\hline \multicolumn{4}{|c|}{$\operatorname{Note}(\mathbf{s}): * * p<0.01$} \\
\hline
\end{tabular}

Table 1.

Confirmatory data analysis and descriptive statistics

\begin{abstract}
which are unique from the scores of other constructs. AVE and the square root of AVE were
\end{abstract}




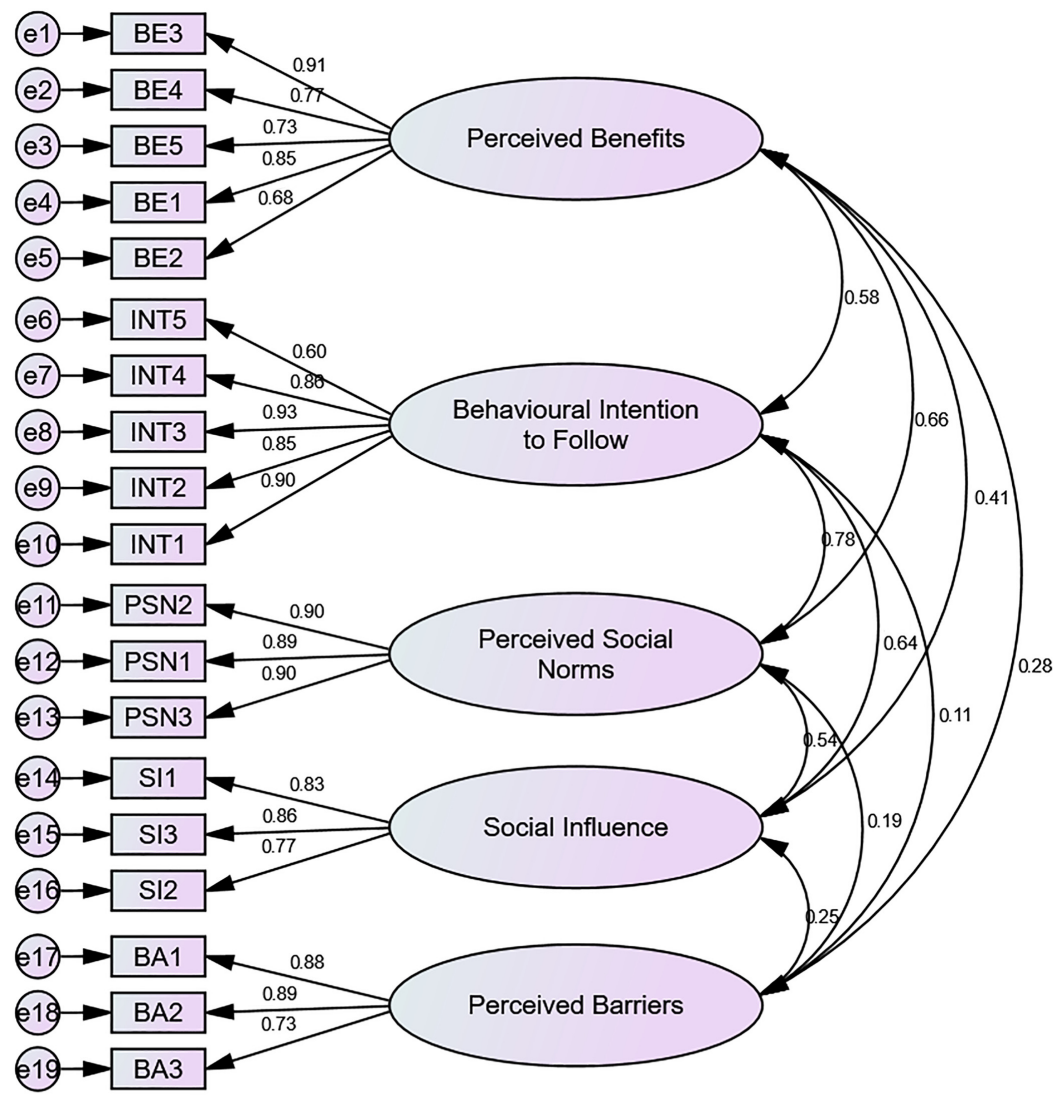

COVID-19 self-protective measures

$\begin{aligned} & \text { Model Fitness Indices } \\ \text { Chi-square }= & 354.281, \mathrm{df}=142 . \mathrm{CMIN} / \mathrm{df}=2.495, \\ \text { RMSEA }= & 0.060, \mathrm{RMR}=0.123, \mathrm{CFI}=0.964,\end{aligned}$

$\mathrm{GFI}=0.915$
Figure 1. Measurement model

higher than interconstruct correlations (Table 2), and the AVE values were larger than maximum shared variance (MSV), which supports the discriminant validity of the constructs and concludes that each construct was unique in this research [19]. Results given in Table 2 conclude that the constructs are free from construct validity issues. The measurement models show an adequate fit because $\chi^{2} / \mathrm{df}=2.495\left(\chi^{2}=354.28 ; \mathrm{df}=142\right)$ is between the cut of range $1-3$. For model fit, the comparative fit index (CFI) and good fit index [GFI] should be closer to 1. Root mean square error of approximation (RMSEA) and root mean square residual (RMR) values should be near 0 [19]. The model fit and values are presented in Figure 1 and show that the model was reasonably fit.

Structural equation modeling was used to check the impact of TPB subscales on the participants' intention to follow COVID-19 SPMs. In total, $70 \%$ of the variation $\left(R^{2}=0.697\right)$ in the participants' intention to follow COVID-19 SPMs were explained by four TPB subscales. The perceived benefits $(\beta=0.100 ; p<0.05)$, perceived social norms $(\beta=0.559 ; p<0.01)$ and social influence $(\beta=0.333 ; p<0.01)$ subscales positively influenced the participant's 


\section{JHR 35,4}

312

Table 2.

Reliability and validity measures

\begin{tabular}{|c|c|c|c|c|c|c|c|c|c|}
\hline Constructs & $\alpha$ & $\mathrm{CR}$ & AVE & MSV & 1 & 2 & 3 & 4 & 5 \\
\hline 1. Perceived benefits & 0.888 & 0.893 & 0.627 & 0.438 & 0.792 & & & & \\
\hline $\begin{array}{l}\text { 2. Behavioral } \\
\text { intention to follow }\end{array}$ & 0.907 & 0.920 & 0.701 & 0.611 & $0.575^{* * *}$ & 0.837 & & & \\
\hline $\begin{array}{l}\text { 3. Perceived social } \\
\text { norms }\end{array}$ & 0.927 & 0.927 & 0.809 & 0.611 & $0.662^{* *}$ & $0.782^{* *}$ & 0.899 & & \\
\hline $\begin{array}{l}\text { 4. Perceived } \\
\text { social influence }\end{array}$ & 0.859 & 0.862 & 0.677 & 0.416 & $0.412^{* *}$ & $0.645^{* *}$ & $0.535^{* *}$ & 0.823 & \\
\hline 5. Perceived barriers & 0.872 & 0.875 & 0.702 & 0.078 & $0.279^{* *}$ & 0.106 & $0.192 * *$ & $0.253^{* *}$ & \\
\hline
\end{tabular}

Note(s): $* * p<0.01$; diagonal value shows the square root of AVE and represented in italic; values in italic represent interconstruct correlations

intentions. However, the perceived barrier $(\beta=-0.114 ; p<0.01)$ subscale influenced the participants' intentions negatively. Among all four subscales, perceived social norms and social influence subscales had more significant predictors of participants' intention to follow COVID-19 SPMs with the highest beta value (Table 3 and Figure 2). Figure 2 also presents the model fit statistics, and the structural model shows reasonable model fit.

As per the Indian health ministry reports, at least $88 \%$ of COVID-19 fatalities in India were among people above the age of 45 years, as of October 2020. In India, $2 \%$ of people who died of COVID-19 were below 30 years [20]. The COVID-19 hospitalization and death rate is nine times lower for 5-17 years old compared to 18-29 years old age groups and two times higher for 30-39 years old age groups compared to 18-29 years old [21]. These discussions indicate that the risk for severe illness from COVID-19 increases with age, where older adults are at highest risk with similar results reported in other countries [21]. With these discussions, the age was split into two groups and the cut-off value was taken as 30 years.

The multigroup analysis (MGA) was conducted to test for significant differences between identical models for different groups (participants above and below 30 years of age) using AMOS graphics. The identified differences can be used to highlight the potential errors if subpopulations are considered as a single homogeneous group by gaining insight into group differences and strategy implementation. In MGA, the structural model was estimated for both groups, including the path coefficients $(\beta 1, \beta 2)$, and significance level and differences in

Table 3.

Multigroup analysis between above and below 30-year-old group samples

\begin{tabular}{|c|c|c|c|c|}
\hline Path name & $\begin{array}{c}\text { Full sample } \\
\beta(\phi \text {-value }) \\
{[n=412]}\end{array}$ & $\begin{array}{c}\text { Above } 30 \text { years } \\
\beta_{1}(\phi \text {-value }) \\
{[n=161]}\end{array}$ & $\begin{array}{c}\text { Below } 30 \text { years } \\
\beta_{2}(p \text {-value }) \\
{[n=251]}\end{array}$ & $\begin{array}{c}\Delta \beta \\
\left|\beta_{1}-\beta_{2}\right| \\
(p \text {-value })\end{array}$ \\
\hline $\begin{array}{l}\text { Perceived benefits } \rightarrow \text { behavioral } \\
\text { intention to follow }\end{array}$ & $0.100\left(0.047^{*}\right)$ & $-0.095(0.363)$ & $0.154(0.011 *)$ & $0.249(0.027 *)$ \\
\hline $\begin{array}{l}\text { Perceived social } \\
\text { norms } \rightarrow \text { behavioral intention to } \\
\text { follow }\end{array}$ & $0.559\left(0.001^{* *}\right)$ & $0.467(0.030 *)$ & $0.561(0.001 * *)$ & $0.095(0.731)$ \\
\hline $\begin{array}{l}\text { Perceived social } \\
\text { influence } \rightarrow \text { behavioral } \\
\text { intention to follow }\end{array}$ & $0.333\left(0.001^{* *}\right)$ & $0.591(0.001 * *)$ & $0.276(0.000 * *)$ & $0.315\left(0.001^{* *}\right)$ \\
\hline $\begin{array}{l}\text { Perceived barriers } \rightarrow \text { behavioral } \\
\text { intention to follow }\end{array}$ & $-0.114\left(0.002^{* *}\right)$ & $-0.072(0.253)$ & $-0.090(0.051)$ & $0.017(0.827)$ \\
\hline$R^{2}$ & 0.697 & 0.797 & 0.661 & 0.136 \\
\hline
\end{tabular}




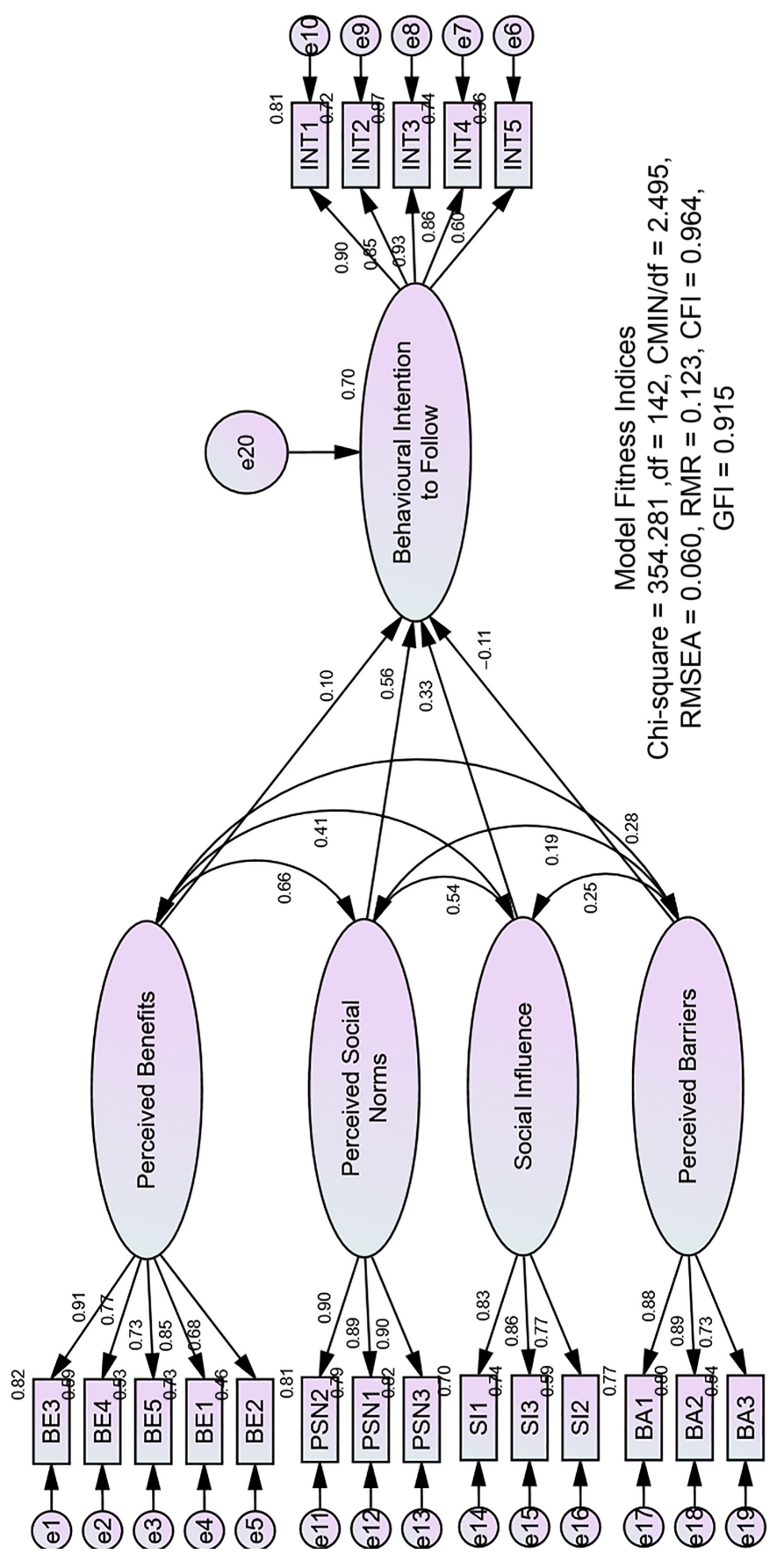

self-protective measures

313

Figure 2. Structural model 
JHR

35,4

\section{4}

path coefficients $(\Delta \beta)$ are presented in Table 3. The $p$-value of the chi-square difference test (unconstrained model $\left[\chi^{2}=600.574\right.$, $\left.\mathrm{df}=284\right]$ and constrained model $\left[\chi^{2}=615.968\right.$, $\mathrm{df}=288]$ is significant $(p<0.01)$, meaning the model differs across the group.

We found that the path between perceived benefits and participants' behavioral intention to follow COVID-19 SPMs was significantly positively stronger for participants above 30 years $(|\beta 1-\beta 2|=0.249 ; p<0.05)$. However, this was not the case for the path from perceived social norms to participants' behavioral intention to follow COVID-19 SPMs $(\mid \beta 1-$ $\beta 2=0.095 ; p=0.731)$. There was a significant difference between the impact of social influence on participants' behavioral intention to follow COVID-19 SPMs $(|\beta 1-\beta 2|=0.315$; $p<0.01$ ), and this link is positive and stronger for participants above 30 years but not for the path from perceived barrier to participants' behavioral intention to follow COVID-19 SPMs $(|\beta 1-\beta 2|=0.136 ; p=0.827)$. In total, $80 \%$ of the variation in participants' behavioral intention to follow COVID-19 SPM was explained by perceived benefits, perceived barriers, perceived social norms and social influence for participants above 30 years, and $66 \%$ of the variation in participants' behavioral intention was explained by independent variables for participants below 30 years. Hence, it can be concluded that participants' age moderates the impact of perceived benefits and perceived social influence and individuals' behavioral intentions of following COVID-19 SPMs, with a $13.6 \%$ difference in model prediction.

\section{Discussions}

The impact of psychometric properties of the TPBS on individual SPMs is addressed in this study. Based on the TPBS, we identified five subscales including perceived benefits, perceived barriers, perceived social norms, social influence and intention to follow COVID-19 SPMs. The validity and reliability measures concluded that these five subscales of TPBS had adequate internal consistency and accuracy. These TPBS were adopted from the original TPB model and modified to the current setting. However, these factors were aligned with the constructs of the original TPB model. Behavior intentions used COVID-19 SPMs and perceived social norms were directly aligned with the TPB model. The perception construct was split into two constructs, namely perceived benefits of following COVID19 and perceived barriers in following COVID-19, to explain an individual's perception toward following SPMs. The items created under the perceived behavioral control construct fell into the intention to follow the COVID-19 SPMs construct [14]. To avoid repetition and improve validity and reliability, the perceived behavioral control construct was dropped in this research. The social influence construct was added to the TPB model. This construct assessed the effect friends, colleagues and peers would have on the individual behavioral intentions. This construct also provided the importance of the friends, colleagues and peers aspect of following COVID-19 protective measures as well as information about the impact of COVID-19 SPMs on reducing COVID-19 spread. The constructs identified within the TPBS provided a better representation of TPB with the incorporation of a new construct that evaluated the impact of social influences on COVID-19 SPM intentions.

\section{Conclusion}

The overall model concludes that perceived benefits, perceived social norms and social influence have a significant positive impact on an individual's intention to follow COVID-19 SPMs. However, the perceived barriers construct negatively influences individuals' intention to follow COVID-19 SPMs and 70\% of individuals' behavioral intention was predicted by those constructs. These outcomes show that subscales of TPBS may be evaluating a unique perspective of behavioral intentions of following COVID-19 SPMs. Therefore, it is suggested 
that researchers and governments use all subscales of TPBS to examine all aspects related to perception toward COVID-19 SPMs.

\section{Implications}

The findings indicate that perceived social norms have a high level of positive impact on individuals' behavioral intentions, followed by social influence, perceived barriers and perceived benefits. Most of the time, individuals rely on society and value the community's opinion when following COVID-19 SPMs. At the same time, family members and peers also play a significant role in influencing an individual's intention to follow SPMs [13]. This information indicates that implementing COVID-19 SPMs within small groups and communities would most likely be more beneficial than an individual setting. From a social influencing construct, it is evident that COVID-19 SPMs reduce the chance of spreading COVID-19. The government interventions to reduce the COVID-19 spread may need to concentrate on providing supportive information regarding the COVID-19 outbreak and different SPMs. More awareness needs to be created on a smaller community scale about the benefits of SPMs since the perceived benefit has an impact on behavioral intentions [11]. Evidently, the cost of SPMs and the time taken to follow SPMs are the main perceived barriers. The government must implement strategies to overcome the barriers by increasing the supply of advanced SPMs. The MGA result indicates that individuals above 30 years have better prediction ability than those below 30 years. Hence, the impact of perceived benefits and social influence on behavioral intention was moderated by the age groups. This result concludes that aged people are highly influenced by social influence and personal benefits. This result helps the government and society to understand the specific challenges and needs faced by older persons in this health crisis.

Governments must fully understand the reasons why individuals are choosing to not follow the SPMs. Based on the findings, the policymakers can develop a multifaceted intervention strategy that could improve the practice of SPMs, which helps to reduce the spread of deadly infections in the future. For example, the impact of perceived benefits of SPMs is less on behavioral intention. Hence, the government can educate individuals, mainly in the less than 30-year-old groups, on the multiple benefits of SPMs and negative aspects of COVID-19. Future researchers can adopt this model and the constructs used in this model to understand SPMs and safety behaviors followed by individuals.

\section{Limitations}

Participants within the study only included individuals aged between 18 and 56 years and validation was done only on this population. In the future, psychometric properties of the TPBS need to investigate other populations including participants above 50 years of age. Similar MGA should be performed based on rural and urban samples. Apart from perceived benefits, perceived barriers, perceived social norms and social influence constructs, other constructs such as perceived susceptibility and fear of infection might be influencing the participants to follow COVID-19SPMs. Mixed-method research needs to be done in the future to understand other potential variables that influence an individual's safety behavior and intention to use SPMs. There is a chance for response bias since the data were collected through self-reported surveys. Future researchers can use data triangulation techniques to reduce response bias. The spread of COVID-19 has been rapid, and governments are taking all practical measures necessary to protect against the virus. We are all responsible for protecting those at higher risk. Steps such as following SPMs may be difficult, but these are the safest means of protecting the vulnerable.

\section{COVID-19 self-protective measures}


JHR

35,4

\section{References}

1. Centers for Disease Control and Prevention [CDC]. People who are at higher risk for severe illness. [cited 2020 Nov 6]. Available at: https://www.cdc.gov/coronavirus/2019-ncov/need-extraprecautions/people-with-medical-conditions.html?CDC_AA_refVal=https $\% 3 \mathrm{~A} \% 2 \mathrm{~F} \% 2 \mathrm{Fwww}$. cdc.gov $\% 2$ Fcoronavirus $\% 2 \mathrm{~F} 2019$-ncov $\% 2$ Fneed-extra-precautions $\% 2$ Fgroups-at-higher-risk. html\%0Ahttps://www.cdc.gov/coronavirus/20.

2. Changoiwala P. Covid-19 threatens to overwhelm India's health care system. Undark [Internet]. 2020 Apr 14 [cited 2020 Nov 6]. Available at: https://undark.org/2020/04/14/covid-19-india/.

3. Dey S. Have to learn to live with Covid-19: Govt. The Times of India [Internet]. 2020 May [cited 2020 Jun 9]. Available at: https://timesofindia.indiatimes.com/india/have-to-learn-to-live-withcovid-19-govt/articleshow/75638429.cms.

4. Afshari M, Poorolajal J, Rezapur-Shahkolai F, Assari MJ, Karimi-Shahanjarini A. Which Factors influence farmers' use of protective measures during pesticides exposure? Workplace Health Saf. 2019 Jul; 67(7): 338-49. doi: 10.1177/2165079919827042.

5. Paakkari L, Okan O. COVID-19: health literacy is an underestimated problem. Lancet Public Health. 2020 May; 5(5): e249-50. doi: 10.1016/s2468-2667(20)30086-4.

6. Anderson RM, Heesterbeek H, Klinkenberg D, Hollingsworth TD. How will country-based mitigation measures influence the course of the COVID-19 epidemic? Lancet. 2020 Mar; 395(10228): 931-4. doi: 10.1016/s0140-6736(20)30567-5.

7. van der Weerd W, Timmermans DR, Beaujean DJ, Oudhoff J, van Steenbergen JE. Monitoring the level of government trust, risk perception and intention of the general public to adopt protective measures during the influenza A (H1N1) pandemic in The Netherlands. BMC Publ. Health. 2011 Jul; 11: 575. doi: 10.1186/1471-2458-11-575.

8. Ajzen I. From intentions to actions: a theory of planned behavior. In: Kuhl J, Beckmann J, (Eds). Action control: from cognition to behavior. Berlin, Heidelberg: Springer; 1985. p. 11-39.

9. Chen MF. Modeling an extended theory of planned behavior model to predict intention to take precautions to avoid consuming food with additives. Food Qual Prefer. 2017 Jun; 58: 24-33. doi: 10. 1016/j.foodqual.2017.01.002.

10. Li ASW, Figg G, Schuz B. Socioeconomic status and the prediction of health promoting dietary behaviours: a systematic review and meta-analysis based on the theory of planned behaviour. Appl Psychol Health Well Being. 2019 Nov; 11(3): 382-406. doi: 10.1111/aphw.12154.

11. Ebrahim SH, Ahmed QA, Gozzer E, Schlagenhauf P, Memish ZA. Covid-19 and community mitigation strategies in a pandemic. BMJ. 2020 Mar; 368: m1066. doi: 10.1136/bmj.m1066.

12. Alwall Svennefelt C, Hunter E, Lundqvist P. Evaluating the Swedish approach to motivating improved work safety conditions on farms: insights from fear appeals and the extended parallel processing model. J Agromedicine. 2018; 23(4): 355-73. doi: 10.1080/1059924X.2018.1501454.

13. Wang F, Zhang J, Mu W, Fu Z, Zhang X. Consumers' perception toward quality and safety of fishery products, Beijing, China. Food Contr. 2009; 20(10): 918-22. doi: 10.1016/j.foodcont.2009. 01.008 .

14. Gabriel EH, Hoch MC, Cramer RJ. Health belief model scale and theory of planned behavior scale to assess attitudes and perceptions of injury prevention program participation: an exploratory factor analysis. J Sci Med Sport. 2019 May; 22(5): 544-9. doi: 10.1016/j.jsams.2018.11.004.

15. Arterberry BJ, Smith AE, Martens MP, Cadigan JM, Murphy JG. Protective behavioral strategies, social norms, and alcohol-related outcomes. Addict Res Theory. 2014; 22(4): 279-85. doi: 10.3109/ 16066359.2013.838226.

16. King KA, Vidourek RA, English L, Merianos AL. Vigorous physical activity among college students: using the health belief model to assess involvement and social support. Arch Exerc Health Dis. 2014; 4(2): 267-79. doi: 10.5628/aehd.v4i2.153.

17. Reid AE, Cialdini RB, Aiken LS. Social norms and health behavior. In: Steptoe A (Ed.). Handbook of behavioral medicine: methods and applications. New York, NY: Springer; 2010. p. 263-74. 
18. Mishra SV, Haque SM, Gayen A. COVID-19 in India transmits from the urban to the rural. Int J Health Plann Manage. 2020 Nov; 35(6): 1623-5. doi: 10.1002/hpm.3047.

19. Hair JF, Black WC, Babin BJ, Anderson RE. Multivariate data analysis: pearson new international edition. 7th ed. Harlow, Essex: Pearson; 2014.

COVID-19 self-protective measures

20. Mullick J, Kaul R. India's Covid-19 toll surpasses 100,000. Hindustan Times [Internet]. 2020 Oct [cited 2020 Nov 5]. Available at: https://www.hindustantimes.com/india-news/india-s-covid-toll100-000/story-sNGsNLCA2MjbpMfjDdFEDI.html.

21. Centers for Disease Control and Prevention [CDC]. COVID-19 hospitalization and death by age. updated 2020 Aug; [cited 2020 Nov 5]. Available at: https://www.cdc.gov/coronavirus/2019-ncov/ covid-data/investigations-discovery/hospitalization-death-by-age.html.

\section{Corresponding author}

Subburaj Alagarsamy can be contacted at: subbu2raj@gmail.com

For instructions on how to order reprints of this article, please visit our website: 